\title{
Model Kampung Arab Santri Bidik Misi Ma'had Al-Jami'ah: Adopsi dan Adaptasi Kampung Arab Pare Kediri
}

\author{
Muhammad Mas'ud, Urifatun Anis \\ Institut Agama Islam Negeri Salatiga \\ Corresponding author: muhammad.masud85@gmail.com
}

\begin{abstract}
This study aims to describe the model and application of the Adopted and adaptive Arab village of the EGYPT Islamic Boarding \& Course for English and Arabic village at Pare Kediri to the students of Ya Bismillah Ma'had Al-Jami'ah Putri IAIN Salatiga mission. The method used is interactive qualitative covering three activities: data reduction, data presentation, and concluding. Data was obtained through observation, interview, and documentation. The results of this study indicate that; 1) learning is carried out with the lecture model, Al-Liqa ', al-tamsil and al-munaqosyah. 2) application of management functions that are adopted includes planning, organizing, leadership, and controlling. 3) the supporting factors in the model of the Arabic village, the santri aiming for the mission of Ya Bismillah Ma'had Al-Jami'ah Putri IAIN Salatiga, namely; the methods used by the ustadz and ustadzah, the curriculum, the materials and teaching materials, the ustadz or ustadzah competences and the holding of learning evaluations. The inhibiting factors include: there are limitations to learning Arabic language tools. Besides that, the ustadz / ustadzah has not found the right model for improving Arabic learning in these institutions due to the students' different educational backgrounds.
\end{abstract}

Penelitian ini bertujuan untuk mendeskripsikan model dan penerapan kampung Arab Adopsi dan adaptif dari kampug Arab EGYPT Islamic Boarding \& Course for English and Arabic at Pare Kediri pada santri bidik misi Ya Bismillah Ma'had Al-Jami'ah Putri IAIN Salatiga. Metode yang digunakan adalah kualitatif interaktif

ISSN 2622-6146 (e) 2622-6138 (p)

(c) Alsina : Journal of Arabic Studies

http://journal.walisongo.ac.id/index.php/alsina 
meliputi tiga alur kegiatan, yaitu reduksi data, penyajian data, dan penarikan kesimpulan. Data diperoleh melalui observasi, interview dan dokumentasi. Hasil penelitian ini menunjukkan bahwa; 1) pembelajaran dilakukan dengan model ceramah, $\mathrm{Al}$ Liqa', al-tamsil dan al- munaqosyah. 2) penerapan fungsi-fungsi manajemen yang diadopsi meliputi perencanaan, pengorganisasian, kepemimpinan dan pengontrolan. 3) faktor pendukung dalam model kampung Arab santri bidik misi $\mathrm{Ya}$ Bismillah Ma'had Al-Jami'ah Putri IAIN Salatiga yaitu; metode yang digunakan oleh para ustadz dan ustadzah, kurikulumnya, materi dan bahan ajarnya, kompetensi ustadz atau ustadzahnya dan diadakannya evaluasi belajar. Adapun faktor penghambatnya antara lain: terdapat keterbatasan alat praktik pembelajaran bahasa Arab, selain itu juga para ustadz/ustadzahnya belum menemukan model yang tepat dalam meningkatkan pembelajaran bahasa Arab di lembaga tersebut disebabkan background pendidikan yang dimiliki oleh santri berbeda-beda.

Keywords: kampung arab; ma'had al-jami'ah; adopsi dan adaptif.

\section{Pendahuluan}

Bidik Misi adalah singkatan dari Beasiswa Pendidikan Mahasiswa Miskin Berprestasi. Program ini diselenggarakan oleh IAIN Salatiga. Bidik Misi tersebut bisa diikuti oleh seluruh mahasiswa IAIN Salatiga melalui tahapan seleksi. Bagi mahasiswa yang lolos seleksi, diwajibkan tinggal di $\mathrm{Ma}^{\prime} \mathrm{had} \mathrm{Al}$ Jami'ah IAIN Salatiga untuk mengikuti kegiatan pembelajaran bahasa Arab selama delapan semester. Bidik Misi IAIN Salatiga mempunyai program unggulan bernama "Ya Bismillah" sebagai icon.

Ya Bismillah adalah singkatan dari Your Association of Bidik Misi Limardhotillah, merupakan sebuah pembelajaran yang anggotanya adalah mahasiswa bidik misi dari semua fakultas di IAIN Salatiga. Program unggulan Ya Bismillah yaitu diprioritaskan pada pembiasaan dan penguasaan berbahasa asing (Arab dan Inggris), dalam hal ini peneliti mengkhususkan pada pembiasaan berbahasa Arab. 
Armai Arif mengatakan bahwa pembiasaan adalah sebuah cara yang dapat dilakukan untuk membiasakan anak didik untuk berpikir, bersikap dan bertindak sesuai dengan tuntunan ajaran agama Islam ${ }^{1}$. Ngalim Purwanto berpendapat bahwa pembiasaan adalah suatu alat pendidikan yang penting sekali, pembiasaan juga merupakan alat satu-satunya dalam pengajaran $^{2}$. Al-Ghazali dalam Zainuddin sangat menganjurkan penggunaan metode pembiasaan yang sesuai dengan perkembangan anak dan yang bertanggung jawab untuk memberikan pembiasaan tersebut adalah orang tua dalam hal ini adalah seorang pendidik. ${ }^{3}$ Walaupun pembiasaan itu seakan-akan dipaksakan, namun sebenarnya akan berguna bagi peserta didik kelak di kemudian hari.

Hal yang menarik dari kampung arab pare adalah di lembaga EGYPT Islamic Boarding \& Course for English and Arabic at Pare Kediri yang mempunyai program mahir berbicara bahasa arab dan mempunyai 4 paket pembelajaran), yakni 1). Paket Prepare to PM Gontor; 2). Paket Belajar Bahasa Inggris; 3). Paket Belajar Bahasa Arab; 4). Paket Bimbel Sekolah ${ }^{4}$.

Kegelisahan dalam Kampung Arab Santri Bidik Misi Ya Bismillah Ma'had Al-Jami'ah IAIN Salatiga adalah masalah dalam hal kurangnya kemahiran dalam berbicara bahasa arab. Hal ini dikarenakan santri yang masuk di IAIN Salatiga mempunyai latar belakang yang berbeda-beda. Ada yang dari Madrasah Aliyah, SMA dan SMK. Berdasarkan hal tersebut di atas maka peneliti melakukan penelitian dengan judul "Model

${ }^{1}$ Armai Arif, Pengantar Ilmu dan Metodologi Pendidikan Islam, (Jakarta: Ciputat Pers, 2002), hal.110.

${ }^{2}$ Ngalim Purwanto, Psikologi Pendidikan, (Bandung: PT. Remaja Rosdakarya, 2003), hal.177.

${ }^{3}$ Zainuddin, dkk. Seluk Beluk Pendidikan Dari Al-Ghazali, (Jakarta: Bumi, 1991), hal.106

4 (https://dilokasi.com/Jawa-Timur/Places/Kampung-Inggris-Egypt-Islamic-Boarding-Camp-1184881). 
Kampung Arab Santri Bidik Misi Ya Bismillah Ma'had AlJami'ah Putri IAIN Salatiga Adopsi dan Adaptif Kampung Arab EGYPT Islamic Boarding \& Course for English and Arabic at Pare Kediri ".

Berdasarkan latar belakang tersebut peneliti dapat merumuskan beberapa masalah, yang pertama bagaimana model kampung Arab adopsi dan adaptif dari kampug Arab EGYPT Islamic Boarding \& Course for English and Arabic at Pare Kediri pada santri bidik misi Ya Bismillah Ma'had Al-Jami'ah Putri IAIN Salatiga? kedua bagaimana penerapan model kampung Arab santri bidik misi Ya Bismillah Ma'had Al-Jami'ah Putri IAIN Salatiga hasil adopsi dan adaptif kampung Arab EGYPT Islamic Boarding \& Course for English and Arabic at Pare Kediri? Dan ketiga Apakah faktor pendukung dan penghambat model kampung Arab santri bidik misi Ya Bismillah Ma'had AlJami'ah Putri IAIN Salatiga adopsi dan adaptif kampung Arab EGYPT Islamic Boarding \& Course for English and Arabic at Pare Kediri?

Peneliti menemukan penelitian yang hampir senada dengan tema yang peneliti ambil yaitu: Penelitian Alvi Dyah Rahmawati (2018), yang berjudul "Manajemen Pengorganisasian Program Kursus Bahasa Arab di Pare Kediri". Hasil penelitian menunjukkan Manajemen pengorganisasian yang dimiliki lembaga kursus bahasa Arab Al-Azhar masih lemah karena beberapa kendala seperti, manajer yang merupakan pemimpin lembaga kursus bahasa Arab Al-Azhar belum memiliki struktur organisasi yang jelas. Manajer hanya memberikan pembagian tugas secara lisan kepada setiap anggota dan tidak membuat bagan struktur organisasi untuk anggota sehingga membuat kedudukan antara bawahan dan atasan tidak dapat kelihatan. Pimpinan bagian yang telah diberikan hak tertentu tidak diberikan jumlah anggota yang jelas untuk 
membantu melaksanakan tugasnya, sehingga sistem pengorganisasiannya kurang tertata rapi. ${ }^{5}$

Penelitian Ratna Sa'idah (2016), yang berjudul "Strategi Pembelajaran Bahasa Arab di ITC (Islamic Training Center) Pare". Hasil penelitian menunjukkan bahwa karakteristik khusus yang membedakan ITC dengan lainnya, yaitu Standar Timur Tengah bisa dilihat dari: Pertama, Lahjah/dialek yang digunakan selama pembelajaran Bahasa Arab selalu menggunakan lahjah Arab, terutama ketika takallum. Kedua, Tarkib al-kalimah/susunan kalimat. Susunan yang digunakan dalam Bahasa Arab baik takallum, qira'ah atau kitabah, harus menggunakan susunan Arab/tarkib Arab fushha, preposisi, muta'addi kalimat tidak ala Indonesia, tapi ala Arab. Ketiga, Materi pembelajaran bersumber dari Al-Qur'an dan Hadits selalu diarahkan pada bimbingan pembelajaran studi keislaman, sebagaimana tertulis ITC (Islamic Training Center) PARE for Islamic Guidance. ${ }^{6}$

Arah yang dituju peneliti adalah "Model Kampung Arab Santri Bidik Misi Ya Bismillah Ma'had Al-Jami'ah Putri IAIN Salatiga Adopsi dan Adaptif Kampung Arab Pare". Berdasarkan hasil penelitian di atas, letak perbedaan peneliti adalah mahir dalam penguasaan bahasa Arab melalui proses pembiasaan.

\section{Metode}

Penelitian ini dimaksudkan untuk memperoleh data secara terukur, tentang model kampung Arab santri bidik misi Ya Bismillah Ma'had Al-Jami'ah Putri IAIN Salatiga dan Kampung Arab Pare. Metode yang digunakan dalam penelitian

5 Alvi Dyah Rahmawati, Manajemen Pengorganisasian Program Kursus Bahasa Arab di Pare-Kediri. (Journal of Arabic Studies UIN Maulana Malik Ibrahim Malang, 2018).

${ }^{6}$ Ratna Sa'idah, Strategi Pembelajaran Bahasa Arab di ITC (Islamic Training Center) Pare, (Journal Realita IAIN Kediri Vol. 14 No. 1 Januari 2016) 
ini adalah kualitatif. Adapun Lokasi Penelitian yaitu Kampung Arab santri bidik misi Ya Bismillah Ma'had Al-Jami'ah Putri IAIN Salatiga dan Kampung Arab Pare Jawa Timur di lembaga EGYPT Islamic Boarding \& Course for English And Arabic at Pare Kediri Jl. Bringin Mulyoasri Tulungrejo, Pare, Kediri, Jawa Timur 64212.

Sumber data dalam penelitian ini dibagi menjadi dua, yaitu: data Primer dan Data Sekunder ${ }^{7}$. Sumber data primer adalah sumber data yang langsung memberikan data kepada pengumpul data Dalam penelitian kualitatif posisi narasumber sangat penting, bukan sekedar memberi respon, melainkan juga sebagai pemilik informasi, sebagai sumber informasi (key informan). ${ }^{8}$ Data Sekunder Merupakan sumber data yang tidak langsung memberikan data kepada pengumpul data, misalnya lewat orang lain atau dokumen. Dalam penelitian kualitatif ini teknik pengumpulan data yang digunakan adalah observasi dan wawancara mendalam/indepth interviews dan dokumentasi dari ketiganya digunakan untuk memperoleh data seperti; letak geografis, keadaan guru dan karyawan, keadaan bangunan dan fasilitasnya, untuk mendapatkan informasi secara lisan dengan tujuan mendapatkan data yang dapat menjelaskan permasalahan penelitian, dapat menghindari kesalahan informasi/ data yang simpang siur Informasi/ data dari hasil wawancara merupakan pelengkap informasi awal, memperoleh informasi secara komprehensif, akurat, jujur, dan mendalam, mendapatkan informasi dan data yang objektif dan berimbang, menggali kemungkinan adanya perspektif baru

${ }^{7}$ Sugiono, Memahami Penelitian Kualitatif: dilengkapi dengan contoh proposal dan laporan penelitian, (Bandung: Alfabeta, 2005), hal.62.

8 Tobroni, Metode Penelitian Pendidikan Pendekatan Kuantitatif, Kualitatif, dan R \& D, (Bandung: Alfabeta, 2001), hal. 134. 
atas suatu masalah dan lain-lain. Model menganalisa data tersebut digambarkan Miles dan Huberman sebagai model interaktif ini yang melipputi: pengumpulan data, penyajian data, reduksi data dan penarikan kesimpulan ${ }^{9}$.

\section{Kampung Arab Pare pada lembaga EGYPT Islamic Boarding \& Course for English and Arabic at Pare Kediri}

Lokasi Kampung Arab Pare pada lembaga EGYPT Islamic Boarding \& Course for English and Arabic at Pare Kediri, Seiring dengan perubahan dan perkembangan zaman yang semakin sarat dengan arus teknologi dan informasi, menumbuhkan pemikiran di kalangan para pengurus EGYPT Islamic Boarding \& Course for English and Arabic at Pare Kediri. untuk mengikuti laju era digitalisasi tersebut. Maka pada tahun 2011 mulai timbul gagasan pendirian sebuah lembaga pendidikan kursus yang mampu mengikuti dan menjawab tantangan zaman dengan tetap berjuang teguh pada kaidah dan syari'at Islam.

Awal mulanya lembaga Egypt hanya memiliki lembaga kursus bimbingan belajar untuk anak-anak SD/SMA dengan fasilitas ruang kelas yang minim yakni parkiran mobil seluas $4 \times 5$ meter persegi. Seiring berjalannya waktu semakin banyak peserta didik yang datang dengan kebutuhan belajar masingmasing, utamanya kebutuhan belajar bahasa inggris dan bahasa Arab. Selain itu ada beberapa pengajar bahasa Arab yang mulai bergabung. Sehingga pemilik lembaga bahasa Arab Egypt mulai membuka kelas untuk bahasa inggris dan bahasa Arab pada tahun 2011. Sejak saat itu lah lembaga ini mulai berkembang pesat dengan jumlah peserta didik yang mulai bertambah. Lembaga Bahasa Arab Egypt terletak di Jl. Bringin No.20 Tegalsari Tulungrejo Pare Kediri Jawa Timur Indonesia.

\footnotetext{
${ }^{9}$ Miles Mathew B. dan A. Michael Huberman, Analisis Data Kualitatif, (Jakarta: Universitas Jakarta, 1992), hal.203.
} 
Keunggulan dari lembaga ini adalah lembaga ini memiliki sistem boarding (karantina) yang tidak hanya mengedepankan pembelajaran bahasa Arab saja melainkan juga untuk pengembangan pribadai utamanya dalam hal ubudiyah. Dengan harapan bahwa lembaga bahasa Arab Egypt dapat melahirkan peserta didik yang mahir dalam bahasa Arab juga berakhlak karimah.

\section{Pembelajaran Kampung Arab Pare pada lembaga EGYPT Islamic Boarding \& Course for English and Arabic at Pare Kediri}

Pembelajaran Lembaga EGYPT Islamic Boarding \& Course for English and Arabic at Pare Kediri yaitu pembelajaran dilakukan setiap hari sesuai jadwal yang telah ditentukan, mulai dari bangun tidur hingga tidur kembali. Istirahat hanya pada waktu sholat, makan, mandi, dan olahraga saja. pembelajaran yang benar-benar intensif karena selain dibimbing, santri juga diwajibkan menghafal kaidah-kaidah sesuai yang ditargetkan. Pembelajaran di lembaga EGYPT ini menyenangkan karena banyak model yang diterapkan oleh para ustadznya meskipun terasa tiada waktu terbuang sia-sia. Semua santri dibangunkan sejak pukul 03.00 WIB untuk melaksanakan shalat dan dzikir hinggi subuh dan setelah subuh masih ada pembelajaran sampai pada pukul 07.00 WIB baru kemudian sarapan, mandi dan yang lainnya kurang lebih 45 menit, setelah itu dilanjutkan pembelajaran yang terkadang dilaksanakan di luar ruangan maupun di dalam ruangan.

Hasil Analisis Pembelajaran Bahasa Arab lembaga EGYPT Islamic Boarding \& Course for English and Arabic at Pare Kediri, mencakup empat Keterampilan yaitu menyimak, membaca, menulis dan berbicara. dengan menguasai empat keterampilan itu santri dapat berbahasa Arab secara pasif maupun aktif juga sebagai alat bantu guna memahami ilmuilmu agama yang ditulis dalam bahasa Arab. Dengan tujuan 
yang sudah ditetapkan, maka akan mempermudah dan memperjelas serta lebih sistematis dalam proses pembelajaran bahasa Arab di lembaga EGYPT Islamic Boarding \& Course for English and Arabic at Pare Kediri.

Pelaksanaan dan pembelajaran mengacu pada kurikulum yang tersedia dan tersusun oleh lembaga EGYPT itu sendiri. Bapak/ibu pengajar dalam pembelajaran Bahasa Arab juga membuat perangkat pembelajaran berupa I'dad Tadris sebelum pembelajaran dimulai agar segala sesuatu yang akan diajarkan tersusun dengan rapi

Sistem pembelajaran bahasa arab menggunakan Sistem small classical, rileks dan direct. Model pembelajaran pada pelaksanaan pembelajaran Bahasa Arab pada lembaga EGYPT Islamic Boarding and Course mengacu pada beberapa metode yaitu: Al-Ilqo': Berdirinya pengajar pada pembelajaran dengan membawa maklumat yang akan diajarkan seperti Muhadhoroh. At-Tamtsil: Pengajar meminta siswa untuk mempraktikkan sedikit apa yang telah dipelajari seperti Muhadatsah. Al-Munaqosyah: Memberikan kata kunci ataupun permasalahan dalam pembelajaran agar diselesaikan secara berdiskusi seperti debat.

\section{Kurikulum lembaga EGYPT Islamic Boarding \& Course for English and Arabic at Pare Kediri}

Kurikulum pada dasarnya merupakan seperangkat perencanaan dan mestinya untuk mengantarkan lembaga pendidikan dalam mewujudkan tujuan yang diinginkan. Dengan demikian kurikulum melingkupi: tujuan, materi pelajaran, metode dan evaluasi. Sebagai lembaga pendidikan pesantren juga telah memuat hal-hal tersebut. Seiring dengan tuntutan zaman dan laju perkembangan masyarakat, pesantren yang pada dasarnya didirikan untuk kepentingan moral, pada akhirnya harus berusaha memenuhi tuntutan masyarakat dan 
tuntutan zaman orientasi pendidikan pesantren perlu diperluas, sehingga menuntut dilakukannya pembaharuan kurikulum yang berorientasi pada kebutuhan zaman dan pembangunan bangsa.

Kurikulum dibuat mulai dari dasar sampai lanjutan dan pengembangan meliputi shorf, nahwu, muhadatsah dan mufrodat. Kurikulum selalu diaplikasikan dan terus dilakukan evaluasi dan penyesuaian untuk kemampuan peserta didik.

Kurikulum terus dikembangkan pada tingkat lanjutan dengan berbagai metode guna pengayaan materi. Mengambil berbagai literature tambahan sebagai bahan ajar yang sesuai. Pada proses mutu dan kualitas, lembaga menggunakan "native speaker" bagi peserta didik dalam memahami berbagai konteks ucapan/percakapan baik langsung maupun lewat visual dan dilakukan percakapan rutin baik bebas maupun tematik.

Masa perkembangan Egypt menjadi Ma'had kali ini, lembaga Egypt melakukan banyak upaya perbaikan mutu lembaga baik secara sistem, kurikulum, materi maupun mutu sumber daya pendidiknya. Dalam sepekan sekali para pengajar Egypt mengadakan program "public Sharing" dengan para santri berkaitan dengan evaluasi, keluhan ataupun masukan dari para santri baik dari segi sarana prasarana, kegiatan belajar mengajar dan yang lainnya. Kegiatan tersebut dilanjutkan dengan rapat evaluasi para pengajar dalam menanggapi dan mencari solusi dari evaluasi yang ada. Selain itu para pengajar juga melakukan studi pustaka dan mengkaji buku-buku berkaitan dengan materi. Dan yang menjadi program terakhir adalah mengirim para pengajar untuk belajar di lembaga bahasa lain dengan tujuan memperbaiki mutu sumber daya pengajarnya dan memperkaya metodologi mengajar.

Kampung Arab Santri Bidik Misi Ya Bismillah Ma'had AlJami'ah Putri IAIN Salatiga 
Lokasi Kampung Arab Santri Bidik Misi Ya Bismillah Ma'had Al-Jami'ah Putri IAIN Salatiga. IAIN Salatiga mulai menerima beasiswa bidikmisi pada tahun 2011, kemudian dibentuk organisasi untuk mahasiswa bidikmisi yaitu Youth Association of Bidikmisi Limardhotillah (Ya Bismillah) pada 12 Agustus 2012. Kemudian pihak kampus mempunyai kriteria khusus untuk mahasiswa bidikmisi yaitu mewajibkan mahasiswa bidikmisi untuk menguasai bahasa asing diantaranya bahasa arab dan bahasa inggris. Untuk mewujudkannya pada liburan semester 5 mahasiswa bidikmisi diberikan pendidikan di Kampung Arab, Pare, Kediri. Dan hasilnya diaplikasikan di program pendidikan Ma'had AlJami'ah Putri IAIN Salatiga.

Kampung Arab Santri Bidik Misi Ya Bismillah Ma'had AlJami'ah putri IAIN Salatiga terletak di lereng gunung merbabu tepatnya di Dusun Kembang Arum, Kelurahan Dukuh, Kecamatan Sidomukti, Kota Salatiga. Suasana sejuk setiap pagi dan pemandangan gunung memberikan semangat sendiri bagi santri.

Tujuan didirikannya Kampung Arab Santri Bidikmisi Ya Bismillah Ma'had Al-Jami'ah Putri IAIN Salatiga untuk memberikan soft skill kepada mahasiswa bidikmisi untuk bisa bersaing dalam era globalisasi yang semakin ketat.

Keunggulan Kampung Arab di Ma'had Al-Jami'ah putri IAIN Salatiga merupakan program harian, sehingga santri terbiasa dengan berbahasa asing. Bukan hanya itu, sistem tutor sebaya juga sangat membantu dalam proses belajar karena tidak ada kesenjangan usia didalamnya.

\section{Pembelajaran Kampung Arab}

Pembelajaran Kampung Arab Santri Bidik Misi Ya Bismillah Ma'had Al-Jami'ah Putri IAIN Salatiga yaitu Setiap pembelajaran yang dilaksanakan dibimbing oleh Ustadz/Ustadzah dengan menggunakan bahasa pengantar 
Arab, kemudian santri diajak mengembangkan sebuah tema yang harus menggunakan bahasa Arab pula, selain daripada itu ustadz/ustadzah memberikan tugas kepada para santri agar menghafal beberapa kosa kata penting dalam tema tersebut. pembelajaran di Kampung Arab Santri Bidik Misi Ya Bismillah Ma'had Al-Jami'ah Putri IAIN Salatiga efektifnya adalah malam karena ketika siang santri kuliah di kampus. Pembelajaran di mulai setelah shalat magrib sampai pukul 21.00 WIB dengan dibimbing oleh para ustadz kemudian santri dibangunkan lagi pukul 03.00 WIB untuk melaksanakan shalat dan dzikir. Bagi santri yang kuliah akan melaksanakan aktifitas perkuliahan dan bagi santri yang tidak ada jam perkuliahan akan melakukan pembelajaran di Ma'had seperti menghafal kosa kata yang telah dibebankan, selain itu juga ada yang menghafal Al-quran dan tugas-tugas lainnya.

Analisis Pembelajaran Kampung Arab Santri Bidik Misi Ya Bismillah Ma'had Al-Jami'ah Putri IAIN Salatiga, Pembiasaan dalam berkomunikasi dengan menggunakan bahasa Arab langsung bersama pengampu dan kawan-kawannya merupakan langkah yang baik untuk memiliki kemahiran berbahasa Arab. Selain pembiasaan berkomunikasi juga dibiasakan dalam menulis karya, cerpen, buletin berbahasa Arab sehingga santri tidak hanya memliki kemahiran kalam namun kitabah dan qiraah juga diperolehnya. Aktivitas pembelajaran bahasa Arab yang menarik kadangkala harus terbentur pada keterbatasan media pembelajaran yang ada di kelas. Persoalan ini tentunya tidak akan terjadi apabila koordinasi yang bagus antara guru bahasa Arab tersebut dengan petugas yang memang bertanggungjawab atas penyiapan media pembelajaran yang diperlukan.

\section{Penerapan Model Kampung Arab}


Penerapannya yaitu pada fungsi-fungsi manajemen yang meliputi perencanaan (planning), pengorganisasian (organizing), kepemimpinan (leading), dan pengontrolan (controlling) adalah sebuah solusi konstruktif dalam menghadapi kendala belum terdistribusinya sumber daya yang ada pada pos-pos tanggung jawab dalam kaitannya dengan pembelajarann bahasa Arab di Kampung Arab Santri Bidik Misi Ya Bismillah Ma'had Al-Jami'ah Putri IAIN Salatiga.

Misalnya, sebagai fungsi pertama dari manajemen sudah bisa diterapkan pada masa-masa penerimaan pengurus atau sebagai pengasuh yang dilakukan dengan analisis kebutuhan Ma'had Al-Jami'ah Putri IAIN Salatiga sehingga input sumber daya manusia yang masuk adalah mereka yang betul-betul dibutuhkan bukan hanya karena faktor "diinginkan"

Hal ini tidak terlepas dari peran manajemen dalam mengelola berbagai sumber daya manusia dalam organisasi demi tercapainya tujuan organisasi yang telah ditetapkan. Bentuk pembiasaan yang dapat dilakukan untuk kemahiran berbicara yaitu melakukan pembiasaan mengasosiasikan makna, mengatur interaksi, siapa harus mengatakan apa, kepada siapa kapan dan tentang apa. Bentuk pembiasaan tersebut dapat berupa: latihan ucapan, latihan ekspresi atau menyatakan fikiran dan perasaan secara lisan. Melihat hasil observasi dan wawancara peneliti dapat simpulkan bahwa bentuk pembiasaan yang dilakukan oleh para Santri Bidik Misi Ya Bismillah Ma'had Al-Jami'ah Putri IAIN Salatiga

Bentuk pembiasaan yang dilakukan di dalam kelas yaitu melakukan proses pembelajaran dan diawali dengan manyanyikan lagu-lagu anak-anak versi bahasa Arab sebagai penyemangat. Para santri melantunkan nadham berbahasa Arab dalam bentuk nyanyian sampai semua santri hadir semua, walaupun tidak hadir semua tapi waktu sudah harus memulai maka nadhaman tersebut dilanjutkan dengan bercerita, kemudian bagi santri yang mendapatkan tugas 
untuk maju ke depan dan bercerita menggunakan bahasa Arab. Aapun tema ditentukan dari pengajarnya. Artinya disini Santri Bidik Misi Ya Bismillah Ma'had Al-Jami'ah Putri IAIN Salatiga diberi bekal dalam pengembangan life skill.

Bentuk pembiasaan pada saat kegiatan pembelajaran yaitu seorang guru (tutor) membiasakan menggunakan metode langsung. Metode langsung diterapkan supaya para santri tidak gagap bahasa Arab karena terbiasa mendengar bahasa Arab.

Bentuk pembiasaan yang dilakukan di kamar adalah melakukan percakapan dengan bahasa Arab dengan sesama Santri Bidik Misi Ya Bismillah Ma'had Al-Jami'ah IAIN Salatiga. Selain bercakap-cakap para santri juga melakukan hafalan mufrodat yang dilaksanakan setiap hari.

\section{Kurikulum Kampung Arab}

Kurikulum yang diajarkan di kampung Arab adalah seputar kehidupan sehari-hari, sedangkan Kurikulum yang ada di ma'had juga seperti di kampung arab, tapi belum efektif, karena silabusnya belum tertulis secara jelas dan terkadang berubah-ubah. Kurikulum dibuat mulai dari dasar sampai lanjutan dan pengembangan meliputi shorf, nahwu, muhadatsah dan mufrodat. Kurikulum selalu diaplikasikan dan terus dilakukan evaluasi dan penyesuaian untuk kemampuan peserta didik. Kurikulum terus dikembangkan pada tingkat lanjutan dengan berbagai metode guna pengayaan materi. Mengambil berbagai literature tambahan sebagai bahan ajar yang sesuai.

Model pengembangan kurikulum yang didapat dari kampung Arab adalah melalui bahasa, seperti vocab (مفردات), khitabah, insya' (insya' thalabi dan insya' ghairu thalabi), Jika di kampung Arab pare model pengembangannya melalui khitobah, jika di ma'had melalui language area dan conversation. 


\section{Faktor Pendukung dan Penghambat Model Kampung Arab}

Berikut faktor pendukung model kampung Arab santri bidik misi Ya Bismillah Ma'had Al-Jami'ah Putri IAIN Salatiga adopsi dan adaptif kampung Arab EGYPT Islamic Boarding \& Course for English and Arabic at Pare Kediri, yaitu adanya kesiapan dari para ustadz dan ustadzahnya untuk selalu mengajar dengan menggunakan penutur bahasa Arab artinya fasilitas dan lingkungan belajar sangatlah memadai. Selain daripada itu beberapa faktor pendukung lainnya diadopsi dari kampung Arab pare diantaranya adalah metode yang digunakan oleh para ustadz dan ustadzah, kurikulumnya, materi dan bahan ajarnya, kompetensi ustadz atau ustadzahnya dan diadakannya evaluasi belajar.

Berikut faktor penghambat dalam peningkatan mutu Pembelajaran Bahasa Arab di Ma'had Al-Jamiah Putri IAIN Salatiga yang ditemukan yakni para guru belum menemukan model yang tepat dalam meningkatkan pembelajaran bahasa Arab. Sebab background pendidikan yang dimiliki oleh santri berbeda-beda.

Berdasarkan data pembelajaran bahasa Arab tersebut, telah peneliti dapatkan mengenai langkah-langkah pembiasaan bahasa Arab yaitu dengan perencanaan terlebih dahulu, dilanjutkan dengan pelaksanaan dan diakhiri dengan evaluasi sebagai bahan pertimbangan untuk langkah selanjutnya, merubah maupun memperbaiki pembiasaan tersebut untuk kedepannya supaya lebih baik lagi.

\section{Kesimpulan}

Model kampung Arab adopsi dan adaptif dari kampug Arab EGYPT Islamic Boarding \& Course for English and Arabic at Pare Kediri pada santri bidik misi Ya Bismillah Ma'had AlJami'ah Putri IAIN Salatiga yang dipakai oleh para ustadz atau ustadzah dengan penerapan pembelajaran seperti ceramah, 
seorang guru memberikan arahan materi dan santri sebagai penerima materi dengan metode Al-Liqa', al-tamsil dan almunaqosyah dapat meningkatkan aspek kognitif, afektif dan psikomotorik santri. Upaya yang dilakukan pengajar dalam meningkatkan mutu pembelajaran Bahasa Arab terkait dengan profesi adalah dengan membuat peraturan untuk selalu berbicara Bahasa Arab dalam beraktifitas khususnya di dalam camp.

Penerapan model kampung Arab santri bidik misi $Y a$ Bismillah Ma'had Al-Jami'ah Putri IAIN Salatiga hasil adopsi dan adaptif kampung Arab EGYPT Islamic Boarding \& Course for English and Arabic at Pare Kediri yaitu pada kurikulum yang digambarkan di lembaga EGYPT Islamic Boarding \& Course for English and Arabic at Pare Kediri dengan mengacu pada penerapan fungsi-fungsi manajemen yang meliputi perencanaan (planning), pengorganisasian (organizing), kepemimpinan (leading), dan pengontrolan (controlling). Hal inilah yang menjadikan pare untuk dijadikan sebagai adopsi dan adaptif dalam pembelajaran bahasa Arab.

faktor pendukung dan penghambat dalam model kampung Arab santri bidik misi Ya Bismillah Ma'had Al-Jami'ah Putri IAIN Salatiga adopsi dan adaptif kampung Arab EGYPT Islamic Boarding \& Course for English and Arabic at Pare yaitu ; pertama dari faktor pendukungnya antara lain: metode yang digunakan oleh para ustadz dan ustadzah, kurikulumnya, materi dan bahan ajarnya, kompetensi ustadz atau ustadzahnya dan diadakannya evaluasi belajar. Kedua yaitu dari faktor penghambatnya antara lain: terdapat keterbatasan alat praktik pembelajaran bahasa Arab, selain itu juga para ustadz/ustadzahnya belum menemukan model yang tepat dalam meningkatkan pembelajaran bahasa Arab di lembaga tersebut. Sebab background pendidikan yang dimiliki oleh santri berbeda-beda. 


\section{Dafar Pustaka}

Alvi Dyah Rahmawati, Manajemen Pengorganisasian Program Kursus Bahasa Arab di Pare-Kediri, (Journal of Arabic Studies UIN Maulana Malik Ibrahim 2018)

Arief, Armai, Pengantar Ilmu dan Metodologi Pendidikan Islam, (Jakarta: Ciputat Press, 2002)

https://dilokasi.com/Jawa-Timur/Places/Kampung-Inggris-Egypt-Islamic-Boarding-Camp-1184881

http://iainsalatiga.ac.id/web/bidikmisi/

Miles Mathew B. dan A. Michael Huberman, Analisis Data Kualitatif, (Jakarta: Universitas Jakarta. 1992)

Ngalim Purwanto, Psikologi Pendidikan, (Bandung: PT. Remaja Rosdakarya, 2003).

Ratna Sa'idah, Strategi Pembelajaran Bahasa Arab di ITC (Islamic Training Center) Pare, (Journal Realita IAIN Kediri Vol. 14 No. 1 Januari 2016).

Sugiono, Memahami Penelitian Kualitatif: dilengkapi dengan contoh proposal dan laporan penelitian, (Bandung: Alfabeta, 2005).

Tobron, 2001, Metode Penelitian Pendidikan Pendekatan Kuantitatif, Kualitatif, dan $R \& D$, Bandung: Alfabeta.

Wawancara dengan para ustadz/Ustadzah yang terkait dengan penelitian ini pada hari Jum'at, 3 Agustus 2018).

Zainuddin, dkk., 1991, Seluk Beluk Pendidikan Dari Al-Ghazali, Jakarta: Bumi. Aksara. 
